\title{
BASAL WATER FILM, BASAL WATER PRESSURE, AND VELOCITY OF TRAVELING WAVES ON GLACIERS
}

\author{
By J. WEERTMAN \\ (Department of Materials Science and Engineering and Department of Geological Sciences, \\ Northwestern University, Evanston, Illinois 60201, U.S.A.) \\ and G. E. BIRCHFIELD \\ (Department of Geological Sciences and Department of Engineering Sciences and Applied \\ Mathematics, Northwestern University, Evanston, Illinois 60201, U.S.A.)
}

\begin{abstract}
Aвstract. The theory of Nye and of Weertman of traveling waves on glaciers is extended to cover the situation where the presence of abundant basal water or increased basal water pressure produces increased sliding of a glacier over its bed. It is found that the ratio of traveling-wave velocity to surface velocity is independent of the amount of water or the basal water pressure. The theoretical value of this ratio, about 4 to 5 , agrees with that found in field measurements (the most recent data are from Mer de Glace). It is concluded that field observations of traveling-wave velocities lend strong support to any glacier sliding theory in which the sliding velocity is proportional to the basal shear stress raised to about a second to fifth power and in which the sliding velocity is a function of either or both the amount of water at the bed of a glacier and the pressure within this water.
\end{abstract}

RÉsumÉ. Film d'eau basal, pression d'eau au fond et vitesse de parcours des ondes cinématiques dans les glaciers. La théorie de Nye et de Weertman des ondes cinématiques est étendue pour couvrir le cas oủ la présence d'une abondante quantité d'eau au fond ou une pression croissante d'eau accroît la vitesse de glissement d'un glacier sur son lit. On trouve que le rapport entre la vitesse de l'onde et la vitesse superficielle du glacier est indépendante de la quantité d'eau ou de la pression de l'eau au fond. La valeur théorique de ce rapport, environ 4 ou 5, concorde avec celui trouvé dans les mesures sur le terrain (les données les plus récentes proviennent de la Mer de Glace). On en conclut que les observations de terrain des ondes cinématiques conduisent à corroborer toute théorie sur le glissement des glaciers dans laquelle la vitesse de glissement est proportionnelle au cisaillement au fond élevé à une puissance deux à cinq et dans laquelle la vitesse de glissement est fonction à la fois de la quantité d'eau au niveau du lit et de la pression à l'intérieur de cette eau.

ZuSAMMENFASSUNG. Wasserfilm sowie Wasserdruck am Untergrund und Geschwindigkeit kinematischer Wellen auf Gletschern. Die Theorie der kinematischen Wellen auf Gletschern von Nye und Weertman wird auf den Fall ausgedehnt. dass infolge des Vorhandenseins reichlichen Wassers oder erhöhten Wasserdrucks am Untergrund das Gleiten eines Gletschers über sein Bett zunimmt. Es ergibt sich dass das Verhältnis der Geschwindigkeit der kinematischen Welle zur Oberflächengeschwindigkeit unabhängig von Wassermenge und -druck am Untergrund ist. Der theoretische Wert dieses Verhältnisses, etwa 4-5, stimmt gut mit den Feldbeobachtungen überein (die neuesten Werte stammen vom Mer de Glace). Daraus wird gefolgert, dass Feldbeobachtungen von Geschwindigkeiten kinematischer Wellen jede Theorie des Gletschergleitens unterstützen, in der die Geschwindigkeit proportional zur Scherspannung am Untergrund, erhoben in die zweite bis fünfte Potenz, ist und in der die Gleitgeschwindigkeit eine Funktion entweder der Wassermenge am Gletscherbett oder des Druckes in diesem Wasser oder beider ist.

\section{INTRODUCTION}

Recent analysis by Lliboutry and Reynaud (1981), as well as that presented in papers cited by them (Lliboutry, 1958; Martin, [1978]), has shown that kinematic waves move down the glacier Mer de Glace at velocities of about five times the annually averaged surface velocity. They regard their results to be inconsistent with the theory of traveling waves given by Nye and 
by Weertman (see references cited by Lliboutry and Reynaud) primarily because this theory (called the NW theory hereafter) uses in its equations a relationship for glacier sliding velocity $S$ where $S$ is proportional to the basal shear stress raised to a power. They rightly point out that. because of seasonal melt-water fluctuations, temperate glaciers, which Mer de Glace is, usually have large seasonal fluctuations in their motion although the basal shear stress remains almost unchanged during a period of one year. Moreover, the long-term annually-averaged surface velocity change at any one place on Mer de Glace does not reflect the long-term change in the basal shear stress.

The NW theory does make the prediction that kinematic waves, depending upon the relative width to depth of a glacier, should travel down glaciers at velocities of the order of $(n-1)$ to $(n+1)$ times the surface velocity. Here $n$ is the power of the Glen creep equation for ice. At moderate stresses the dimensionless constant $n$ is approximately equal to three. At stresses above about 2 to $3 \mathrm{MPa}$ (20 to 30 bars) power-law creep breaks down and the effective value of $n$ is larger the larger is the stress. The stress around glacier bed obstacles can be expected to be of the magnitude where the exponent $n$ should have values of the order of four to five. Thus when sliding is a major mechanism of a glacier's motion, kinematic wave velocities of the order of five times the surface velocity is a reasonable expectation according to the NW theory. But the criticism of Lliboutry and Reynaud suggests that this apparent agreement could be for the wrong reason.

The alternative explanation of the observed kinematic wave velocities found for Mer de Glace that is presented in the paper of Lliboutry and Reynaud is, as they admit, tentative and incomplete. Because it is developed for the special conditions of Mer de Glace it would not necessarily account for the measurements of traveling wave velocities, which are of the order of four times the surface velocity, found for other glaciers (Sharp, 1954).

The NW theory of traveling glacier waves is rather general and actually is not restricted in its application to some particular glacier sliding theory. Although it was developed by making use of a glacier sliding law that was derived for the condition that a large amount of water is not present at a glacier bed, there is no reason why this theory cannot be extended to sliding laws developed under the assumption that a large amount of water is present at the bed. It is the purpose of this paper to do just that. It is shown in the sections that follow that the predicted velocity of kinematic glacier surface waves is virtually the same as that given in the earlier papers.

\section{THEORY}

Consider a glacier which is wide enough that spatial velocity variations in the transverse direction are not important. Let $S$ again be the sliding velocity and $U$ be the component of the surface velocity that arises from internal ice deformation. The surface velocity is the sum of $S$ and $U$. The velocity term $U$ is given by

$$
U=U_{0}\left(\sigma / \sigma_{0}\right)^{n}
$$

where $\sigma$ is the basal shear stress, $n \approx 3$ for ice subjected to moderate stress, and $U_{0}$ and $\sigma_{0}$ are constants with dimensions of velocity and stress respectively. (A set of two constants of which one is redundant, rather than only one constant, is used in this equation and other equations for dimensional clarity.) In the NW theory the sliding velocity $S$ was taken to be given by the 
equation

$$
S=S_{0}\left(\sigma / \sigma_{0}\right)^{m}
$$

where $S_{0}$ is another constant with dimension of velocity. The dimensionless exponent $m$ in Equation (2) is equal to

$$
m=\left(n^{\prime}+1\right) / 2
$$

where $n^{\prime}$ in Equation (3) is the effective value of $n$ at the stress level around a bed of obstacles.

The kinematic wave velocity $W$ of a perturbation in the ice thickness derived in the NW theory from Equations (1) and (2) is

$$
W=(m+1) S+(n+1) U .
$$

(In Lliboutry and Reynaud (1981) it is stated that in the Weertman paper on traveling waves only the sliding motion of a glacier is used. This is an oversight in their paper. The Weertman theory is a general one that considers both internal motion and sliding motion and considers as well the diffusional widening of surface waves and the exponential time dependence of surface perturbations.)

The kinematic wave velocity given by Equation (4) is that found from perturbation theory when the diffusional broadening term is ignored. In the " $\mathrm{N}$ " form of this theory the diffusional term is $\partial(D \partial \delta h / \partial x) / \partial x$ where $D$ is the "diffusion" constant, $\delta h$ the perturbed ice thickness, and $x$ is the distance down a glacier. When $D$ is not independent of $x$ this term is equal to the sum $(\partial D / \partial x) \partial \delta h / \partial x+D \partial^{2} \delta h / \partial x^{2}$. The first of these two terms adds a contribution $-(\partial D / \partial x)$ to the value of the kinematic wave velocity. In the "W" form of the theory the equivalent term has been given a more explicit expression (when sliding dominates the glacier motion). In it the kinematic wave velocity, instead of being equal to $(m+1) S$, is equal to $(m+1) S-\{(m+1) S(\beta-\alpha) / \alpha\}-$ $\{A(m-1) / \alpha\}$. Here $\beta$ is the average slope of the bottom ice surface, $\alpha$ the average slope of the top ice surface ( $\beta$ and $\alpha$ are positive for a down-hill slope), and $A$ is the accumulation rate. When the ratios $(\beta-\alpha) / \alpha$ and $A / S \alpha$ are small compared to one the correction to the traveling-wave velocity from the diffusion term is small.

\subsection{Effect of water}

There are two ways that water can increase the sliding velocity of a glacier. The presence of large amounts of water at the bed causes the ice to be separated from the bed. Consequently the effective bed that the glacier ice "sees" is smoother than the actual bed. It is reasonable to expect that the smoother the bed the faster a glacier will slide over it. Smoothing the bed, of course, produces larger deviatoric stress concentrations at the up-stream sides of the remaining obstacles. The resultant increase in creep flow rate around these obstacles produces faster sliding velocities.

There is a second way that the deviatoric stress at the up-stream side of obstacles can be increased without smoothing out the bed appreciably. It is shown below that, from a balance of forces argument, if a water cavity exists on the down-stream side of a protuberance, increasing the water pressure within the cavity, leads to an increase in the deviatoric stress that acts on the up-stream side of the protuberance. Therefore, increasing the pressure of the water at the bed that is connected to down-stream cavities must increase the sliding velocity. Thus, increasing the amount of water at a glacier bed or increasing the water pressure at the bed or increasing both together should cause the sliding velocity of a glacier to increase. 
(a) Water film

The first way water increases the sliding velocity is shown in Figure 1. A glacier bed can be expected to contain irregularities of all sizes in its profiles. The presence of a water film of appreciable thickness has the effect of smoothing the bed profile so that irregularities of a scale of the order of or smaller than the water-layer thickness are effectively removed over a major fraction of the glacier bed. The effective bed that the glacier ice "sees" is smoother than the real bed and consequently the glacier slides over the effective bed with a faster velocity at a given value of the basal shear stress. The sliding velocity $S$ is estimated by Weertman (1969) to be given by

$$
S=S_{0}\left(\sigma / \sigma_{0}\right)^{m}\left(1+10 d / d^{*}\right)
$$

where $d$ is the average thickness of the water film and $d^{*}$ is the height of the obstacles that offer the major resistance to sliding when $d \ll d^{*}$. The value of $d^{*}$ is given by (Weertman, 1969)

$$
d^{*}=d_{0}\left(\sigma_{0} / \sigma\right)^{\left(n^{\prime}-m\right)}
$$

where $d_{0}$ is a constant with dimension of length. Thus when $d \gg d^{*} / 10$ Equation (5) reduces to

$$
S \simeq S_{0}\left(10 d / d_{0}\right)\left(\sigma / \sigma_{0}\right)^{n^{\prime}} .
$$

(it should be noted that the presence of "little" bumps on the tops of the "large" bumps of Figure 1, which are not drowned by the water film and which may be smaller than $d^{*} / 10$, will not alter appreciably the average sliding velocity given by Equation (7). The ice flow around the larger bumps takes place primarily by creep deformation over a length scale of the order of the size of the larger bump. This scale length is greater than the size of the smaller bumps. So long as the valley bottoms around the larger bumps are filled sufficiently with water that the "friction" stress there has a very low value, the ice flow around the larger obstacles is not inhibited appreciably by the zones of higher friction stress at the tops of these obstacles.)

If Equation (7) is substituted into the NW theory, the velocity of traveling surface waves on glaciers becomes

$$
W=\left(n^{\prime}+1\right) S+(n+1) U .
$$

If, because of the copious presence of water at the base of a glacier, the sliding term $S$ is much
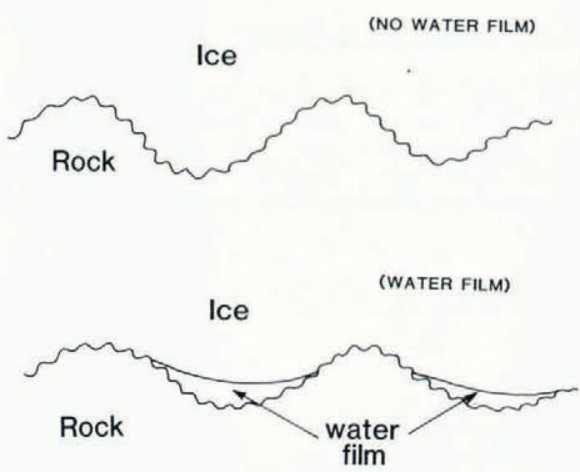

Fig. 1. Longitudinal cross-section of a glacier bed with and without a water film showing irregularities of two different sizes. The actual bed contains all sizes. A transverse cross-section would have a similar appearance. 
larger than the internal deformation term the ratio $W / S$ is

$$
W /(S+U) \approx W / S=n^{\prime}+1 .
$$

This ratio is independent of the actual value of the water-film thickness and thus of the amount of water present at a glacier bed. Thus the fact that the surface velocity of a glacier may vary widely during the course of a year, because of large changes of the amount of melt water present at the bed, does not change the value of the ratio of surface-wave velocity $W$ to surface velocity. Even when the average value of the velocities $U$ and $S$ are comparable, this ratio can only vary between the limits of $n+1$ and $n^{\prime}+1$ or between the limits of $\left(n^{\prime}+1\right) / 2$ and $n^{\prime}+1$. Thus despite the fact that the surface velocity may change drastically while the basal shear stress remains virtually constant, the ratio of the traveling wave velocity to surface velocity is almost constant and has a value of approximately what is observed. This conclusion should apply to both the ratio of the instantaneous value of the surface-wave velocity (which has never been measured) to the instantaneous surface velocity as well as to the annually averaged values of these quantities.

\section{(b) Water pressure}

The second way that water may be able to influence the sliding velocity is through the effect of water pressure. This pressure effect can be explained with the aid of Figure 2. Figure 2 shows an individual bump on a glacier bed. No other bump occurs within a distance $L$ from this one. If $\sigma_{1}$ is the average local value of the shear stress out to the distance $L$ then the bump must support a horizontal force $\sigma_{1} L^{2}$ if the rock-ice interface is frictionless. Let $P_{\mathrm{u}}$ be the pressue at the ice-rock interface on the up-stream side of the bump and $P_{\mathrm{w}}$ be the water pressure in a waterfilled cavity on the down-stream side of the bump. The values of $P_{\mathrm{u}}$ and $P_{\mathrm{w}}$ have to be such that

$$
\left(P_{\mathrm{u}}-P_{\mathrm{w}}\right) a^{2}=\sigma_{1} L^{2}
$$

where $a^{2}$ is the cross-sectional area of the bump and $a$ is its average dimension. The deviatoric stress on the up-stream side of the obstacles is of the order of $P_{\mathrm{u}}-P_{1}$ where $P_{1}$ is the average local value of the hydrostatic pressure within the ice out to a distance of the order of $L$. By Glen's creep law, the creep rate of ice on the up-stream side of the bump is proportional to $\left(P_{\mathrm{u}}-P_{1}\right)^{n^{\prime}}$. The sliding velocity of ice past the bump is proportional to this creep rate and to the size of the bump. Thus $S$ is equal to

$$
S=S_{0}^{*}\left(\left[\sigma_{1}(L / a)^{2}+P_{\mathrm{w}}-P_{1}\right] / \sigma_{0}\right)^{n^{\prime}}
$$

where $S_{0}^{*}$ is the constant. It should be noted that Equation (11) is valid when cavities are so large that further size changes of the cavities, and the pressure changes on the ice sole where it is still in "contact" with the down-stream face of obstacles, can be neglected.

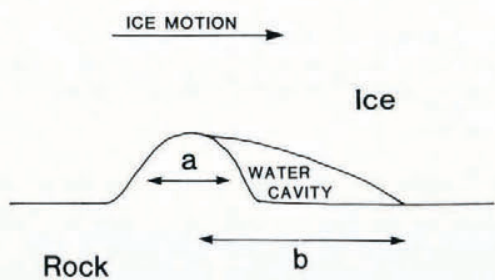

Rock
Fig. 2. Cross-section of an isolated bump at a bed with a water cavity behind it. Dimensions of bump are of the order of distance a in all three directions. 
The length $b$ that the water cavity has in Figure 2 can be found by calculating how fast a cavity closes under a differential pressure of $P_{1}-P_{w}$. Thus the distance $b$ is of the order of

$$
b \approx a\left[\left(\sigma_{1}(L / a)^{2}+P_{\mathrm{w}}-P_{1}\right) /\left(P_{1}-P_{\mathrm{w}}\right)\right]^{n^{\prime}} .
$$

The largest value $P_{\mathrm{w}}$ can have is equal to $P_{1}$ and the smallest value $P_{\mathrm{w}}$ can have is when there is no cavity. In the latter case $P_{\mathrm{w}}=P_{1}-\frac{1}{2} \sigma_{1}(L / a)^{2}$, a result required from the symmetry of the ice flow around an obstacle.

The component of the traveling-wave velocity that arises from the sliding motion $W_{\mathrm{s}}$ is given by the NW theory from the equation

$$
W_{s}=\partial(S h) / \partial h
$$

where $h$ is the ice thickness. If Equation (11) is placed into Equation (13) and the basal shearstress term $\sigma_{1}$ as well as the term $P_{1}$ are considered to be proportional to the ice thickness $\left(\sigma_{1}\right.$ is also proportional to the surface slope), the following equation for $W_{\mathrm{s}}$ is obtained:

$$
\left.W_{\mathrm{s}} / S=1+n^{\prime}\left[\sigma_{\mathrm{l}}(L / a)^{2}+h \partial P_{\mathrm{w}} / \partial h-P_{1}\right) /\left\{\sigma_{\mathrm{l}}(L / a)^{2}+P_{\mathrm{w}}-P_{1}\right\}\right] .
$$

The term $h \partial P_{\mathrm{w}} / \partial h$ can be expected to be of the order of $P_{\mathrm{w}}$. That is, the thicker a glacier the larger the water pressure is likely to be. If $P_{\mathrm{w}}$ is proportional to the ice thickness, then $P_{\mathrm{w}}$, obviously, is exactly equal to $h \partial P_{\mathrm{w}} / \partial h$ even if the constant of proportionality varies with distance along the glacier. Since $P_{\mathrm{w}}$ is expected to vary between the limits of $P_{1}$ and $P_{1}-\frac{1}{2} \sigma_{1}(L / a)^{2}$ and since both the terms $P_{1}$ and $\sigma_{1}$ are proportional to $h$, it is reasonable to expect that $h \partial P_{\mathrm{w}} / \partial h \approx P_{\mathrm{w}}$. Thus Equation (14) reduces to

$$
W_{\mathrm{s}} / S \simeq 1+n^{\prime} .
$$

The ratio $W_{\mathrm{s}} / S$, at least to a first approximation, is independent of the water pressure and has the same value as that given by Equation (9).

\section{Discussion}

The results of the previous section show that it is reasonable to expect that the ratio of the traveling-wave velocity to surface velocity should be almost a constant despite the fact that the surface velocity may change by very large amounts during the passage of the seasons. The expected value of this ratio, $1+n^{\prime}$, is of the order of the observed one.

The large velocity changes of temperate glaciers presumably are due to fluctuations of the amount of water at the bed of a glacier and to fluctuations of the pressure of this water. The explanation of an increase in sliding velocity by an increase in the amount of water at the bed (an increase in the average thickness of the water film) is very straightforward, and the part of our paper dealing with the water-film effect is reasonably certain in its conclusion. On the other hand it is obviously a gross simplification to consider the effect of water pressure on the sliding motion by looking at only one bump at the bed and considering what happens there to be representative of what happens everywhere. Irregularities come in all sizes and a reasonably complete theory must consider what the water pressure is behind bumps of all sizes and the flow of water between all sizes of cavities. This theory does not yet exist. Lliboutry's sliding theories (Lliboutry, 1979) which have focused on the water-pressure question indicate that the final and complete theory will undoubtedly be a rather complicated one. 
Nevertheless, the simple picture of Figure 2 presents, we believe, the essence of the waterpressure effect. Increasing the water pressure insures that the deviatoric stress on the up-stream side of obstacles must increase. But, it should be noted, the deviatoric stress always remains proportional to the basal shear stress. (This condition is essential to our analysis.) It is this stress that causes ice to flow around an obstacle. The larger this stress can be made the faster the glacier slides. The largest increase that a change in the water pressure can produce is the factor $2^{n^{\prime}}$, which is of the order of 8 to 32 for values of $n^{\prime}$ in the range of $3 \leqslant n^{\prime}<5$. The increase in the sliding velocity that is caused by increasing the thickness of the water film, on the other hand, is unlimited.

It should be emphasized that in this paper the glacier bed is considered to have a full spectrum of obstacles sizes. If a glacier bed is used which does not contain irregularities with sizes larger than some cut-off size, the sliding velocity becomes independent of basal shear stress and can have infinite values once the film thickness is close to this cut-off size. The water pressure is equal to the overburden pressure when the film thickness has this value. Some sliding theories of Lliboutry have this result and seem to require such a bed. We also have not considered the case of relatively thin glaciers that are likely to have many air-filled, rather than water-filled, cavities at their beds. Because the deviatoric stress at the up-stream side of obstacles whose down-stream side contains an air cavity is proportional to the basal shear stress, our results should apply equ ally well to such glaciers.

The ratio $W_{\mathrm{s}} / S$, which to a first approximation is equal to the ratio of the annually averaged traveling-wave velocity to surface velocity of any glacier whose yearly motion occurs primarily during periods of abundant basal melt water, is independent of both the amount of water present at the bed and to the pressure within this water. Moreover, the predicted value of this ratio, namely $1+n^{\prime}$, is the same for the water-pressure case and the water-film case. It is not possible, therefore, to decide using a measured value of the traveling-wave velocity and of the surface velocity whether water-film thickness or water pressure is the more important factor in producing an increased sliding velocity in a glacier. Nevertheless, the fact that the observed traveling-wave velocities do agree reasonably with predicted values adds very important field support to all theories of glacier sliding in which the predicted sliding velocity is always proportional to the basal shear stress raised to a power of the order of two to five and the sliding velocity increases when either the amount of water or the water pressure or both increase at the bed. (It is also possible to have the sliding velocity increase while the water pressure decreases if an increase in the amount of water counteracts the effect of a decrease in water pressure.) The traveling-wave observations are almost inexplicable to any theory in which the sliding velocity does not have this dependence on basal shear stress.

\section{ACKNOWLEDGEMENTS}

This research was sponsored in part by funding from the Climate Dynamics Section of the National Science Foundation under Grants ATM-78/3961 and ATM-81/1138. The figures were drafted by Cheril Cheverton. 


\section{REFERENCES}

Lliboutry, L. A. 1958. La dynamique de la Mer de Glace et la vague de 1891-95 d'après les mesures de Joseph Vallot. Union Geodésique et Géophysique Internationale. Association Internationale d'Hydrologie Scientifique. Symposium de Chamonix, 16-24 sept. 1958, p. 125-38. (Publication No. 47 de l'Association Internationale d'Hydrologie Scientifique.)

Lliboutry, L. A. 1979. Local friction laws for glaciers: a critical review and new openings. Journal of Glaciolog!' Vol. 23, No. 89, p. 67-95.

Lliboutry, L. A., and Reynaud, L. 1981. "Global dynamics" of a temperate valley glacier, Mer de Glace, and past velocities deduced from Forbes' bands. Journal of Glaciology, Vol. 27, No. 96, p. 207-26.

Martin, S. [1978.| Analyse et reconstitution de la série des bilans annuels du glacier de Sarennes, sa relation avec les fluctuations du niveau de trois glaciers du Massif du Mont-Blanc (Bossons, Argentière, Mer de Glace). Zeitschrift für Gletscherkunde und Glazialgeologie, Bd. 13, Ht. 1-2, 1977, p. 127-53.

Sharp, R. P. 1954. Glacier flow: a review. Bulletin of the Geological Society of America, Vol. 65, No. 9, p. 831-38.

Weertman, J. 1969. Water lubrication mechanism of glacier surges. Canadian Journal of Earth Sciences, Vol. 6, No. 4, Pt. 2, p. $929-42$. 